\title{
Design, Implementation, and Outcomes of a Comprehensive Professional De- velopment Program for Post-Graduate Studies in Engineering
}

\section{Prof. Laleh Behjat}

Dr. Laleh Behjat is an associate Professor in the Department of Electrical and Computer Engineering at the University of Calgary. Her research interests include designing computer chips, electronic design automation and developing software for computer hardware. She has won several awards for her work on the development of software tools for computer engineering. In addition, Dr. Behjat has a passion for increasing the statues of women in Science, technology, engineering and mathematics (STEM). Dr. Behjat was the recipient of 2015 Association of Professional Engineers and Geoscientists of Alberta (APEGA) Women in Engineering Champion Award.

\section{Dr. Milana Trifkovic, University of Calgary}

Milana Trifkovic is an Assistant Professor in the Department of Chemical and Petroleum engineering at University of Calgary. Her research interests include process and material design and hierarchical control of complex processes.

\section{Robyn Paul, University of Calgary}

Robyn is a Master's student researching engineering leadership education at the University of Calgary. She graduated from Manufacturing Engineering in 2011 and worked in industry for a few years before returning to school.

\section{Karen Andrea Canon-Rubio, University of Calgary}

Ms. Stephanie Hladik, University of Calgary

Stephanie Hladik is a M.Sc student in Electrical and Computer Engineering at the University of Calgary. Through her research she is exploring topics related to the integration of engineering into K-12 curricula. In particular, she is interested in bringing electrical engineering, programming, and the engineering design process into K-12 education. Aside from her research, Stephanie also participates regularly in outreach programs to promote STEM topics in classrooms and beyond. 


\title{
Design, Implementation and Outcomes of a Comprehensive Professional Development Program for Post Graduate Studies in Engineering
}

\begin{abstract}
This paper describes a 5-year project in which we defined a gap in development of professional skills in postgraduate engineering education, identified effective methods for developing students' professional skills, implemented a series of two required courses to develop them, and evaluated the effectiveness of the program. The courses content, assessments, teaching methodologies, and outcomes are discussed in this paper. Our 5 years of program evaluation are summarized. We describe how our program has been extended to multiple departments in the faculty of engineering and evolved from the model of individual to joint classes and teamteaching. Finally, we discuss effectiveness of those modes of teaching.
\end{abstract}

\section{Introduction}

Skills such as communication, professionalism, ethics, and project management are not specifically taught within the engineering graduate curriculum. These skills, referred to as soft skills or professional skills, are often assumed to be acquired as a result of performing academic tasks and "constant" communication with other graduate students and faculty members ${ }^{[1]}$. The Canadian Association of Graduate Studies (CAGS) recognizes the duty and responsibility of universities to train these soft skills. CAGS defines professional development as knowledge that must be provided along with practice and continuous coaching within the graduate programs ${ }^{[2]}$.

During their first year of graduate studies, many engineering students feel they are not prepared and do not have necessary research skills such as communications skills and organization ${ }^{[3]}$. Communication is a particularly important area of professional skill development, especially with high numbers of foreign language graduate students in engineering. Studies have shown that mentoring can be an effective approach for improving communication skills of international students, including activities such as Toastmasters clubs, formal academic support, and informal peer discussion groups ${ }^{[4,5]}$.

Many universities have begun to recognize the value of professional development programs in the balance of work/study/life across different disciplines ${ }^{[1,6,7]}$. The four most relevant professional attributes for engineering PhDs were identified in one study as creativity, good communication skills, multi-disciplinarity, and strong analytical skills ${ }^{[8]}$. One recommendation to promote these skills, as well as skills like leadership and flexibility in the global environment, is to provide graduate students with more opportunities to interact with industry professionals ${ }^{[9]}$.

Universities which have acted on this need have mostly implemented preliminary surveys, supplementary workshops, and online resources ${ }^{[1,6,7,10]}$. One pilot study was conducted at Purdue University to provide graduate students with a graduate level course called "Preparing Future Professionals" ${ }^{[11,12]}$. This course focused on the following five areas: 1) research and technical competences; 2) leadership, management, and organizations; 3) interpersonal, communication, and professional skills; 4) career management and advancement; and 5) career and life balance.

The graduate students, departments, and faculties do recognize the importance of integrating professional development within the graduate curriculum ${ }^{[10]}$, yet the feedback on these 
initiatives have reported low student acceptance and demand of opportunities to learn and develop such skills ${ }^{[1,10]}$. Though, overall it is evident that there is a scarcity of literature on professional development in engineering graduate education. In this paper, we describe the design of the professional program at the University of Calgary, and the results from an analysis of feedback data from the past two years. The program builds on the student's previouslydeveloped skills and attitudes; provides feedback and awareness of what those are; and provides practice with feedback to alter the skill toward target skills.

\subsection{Motivations}

At our institution, professional skills are taught indirectly by student supervisors and graduate course teachers. Supervisors are tasked with defining innovative research projects, engaging students in industrially relevant projects, and encouraging dissemination through journal publications and conference presentations. Whereas, graduate course teachers encourage innovation and team work through assigning open-ended problems and group projects.

The graduates from our program were expected to become skilled researchers and have desirable professional skills through the aforementioned activities. Yet, the faculty observed that our students had unexpected difficulties. The majority of our students struggled to effectively present their research in an oral or written form, and had difficulties working in a team environment. The problem was escalated at the postgraduate level in comparison to undergraduate, as many of our graduate students are international students and faced added difficulty due to differences in language, culture, and education.

To address these problems, we began by asking what attributes we want our students to have. We identified the following as the main attributes: effective communication, professional behaviour, effective research methodology, proactive career planning and staying current on world of engineering.

During the development stage of the program we posed the following questions: When should we implement these courses in the program? How extensive would our interventions be? How would we assess a student's skill? How could we ensure that the students could use their skills in other contexts? Is the program scalable to other departments, faculties and beyond?

Answers to these questions, along with the desired attributes, were key drivers in the content development for two courses in our graduate programs. The courses are delivered through one weekly 75 min class ( 0.5 credit units) in the Fall and Winter terms. Currently, course enrolment is mandatory for graduate students in three of the engineering departments (155 total students). Their design, implementation and outcomes are discussed in detail in the following sections.

\section{Design}

Students enroll in the Professional Development program in the first two semesters of their graduate degree. The first course focuses on reviewing health \& safety, communication, interpersonal relationships, and presentation skills (oral and written). The second course furthers the presentation skills, addresses research methodologies, teaches technical writing skills and the peer review process, and discusses career planning and entrepreneurship. In the following, we elaborate on these topics and discuss how they relate to the graduate attributes. 


\subsection{Academics}

This attribute relates to gathering of advanced knowledge, research, courses, background study, research methodology, and writing a thesis. Students acquire advanced knowledge and learn about their research topic by working with their supervisors and taking required technical courses. Hence, these skills are not covered in the classes. The academic attributes within the course are: background study, research methodologies and effective writing skills.

As a part of the background study, students become familiar with managing citations, performing an impact study, writing an impact study abstract, and review process. Then, an interactive workshop on impact study is performed. All faculty members are asked before the class to nominate a set of impactful papers in their research area. During the class, the instructors discuss how to perform an impact study. Finally, students perform a study on one of the nominated papers and write a short abstract.

To teach the most effective research methodologies, students take several workshops on forming ideas, formulating good questions, managing assumptions, and testing hypotheses. Pitfalls such as personal bias and lack of falsification are discussed. By the end of the second term, the students must formulate a research question and hypothesis, and write an abstract on it.

Effective writing skills is heavily emphasized in this course. The students become familiar with best writing practices as well as effective ways to manage the time to write. In addition, the students write short (1 page) and extended abstracts and review each other's work. After the peer review process, the students gather in a technical program committee style meeting and decide on the best abstracts from the class.

\subsection{Presentation skills}

Presentation attributes include: planning and delivery of a presentation, graphical design of posters and power point presentations, and voice projection and body language.

During the planning a successful presentation workshop, issues are discussed such as structuring a talk, building an idea map, and tuning a presentation for the right audience. During the workshop, students prepare an effective elevator pitch and present it to their peers ${ }^{[13,14]}$.

Graphical design of posters and slides includes interactive examples of issues such as visual tensions, concentrated focus, and flow of the slides. Students also learn graphical presentation basics such as focus, flow, and font, as well as data visualization techniques. Students apply these visualization methods during an interactive class to improve their presentation slides ${ }^{[15]}$.

To teach voice projection and body image, a professor is invited from the drama department. During this class, students learn on how to project their voice and how to be aware of their body language in an active learning class environment. Students also practice delivering 30 second elevator pitch and perform a 3-minute thesis (3MT) style competition ${ }^{[16]}$. 


\subsection{Professionalism}

Professional attributes taught in the class include: building effective supervisory relationships, conflict management, communication styles, and academic integrity.

To build an effective supervisory relationship, first a workshop on Life as a graduate student is offered. Students hear from senior graduate students on the challenges, opportunities, and support throughout grad studies. Additional topics of discussion include: 1) how to keep a happy and healthy life style, 2) where to get help? and 3) what are the opportunities for leadership or scholarship? The discussions are conducted in round table groups to provide an open format.

The second workshop focuses on the supervisory relationship. This workshop is designed to teach students on their responsibilities as graduate students, and to give them a toolkit to build a successful relationship with their supervisor(s)/academic advisor(s). Practical issues such as setting regular meetings, preparing agendas and minutes taking are. More difficult issues such as conflict management and resolutions are also touched on. The workshop is an active learning environment where students role-play different situations ${ }^{[17]}$.

Conflict management in a research environment is an important and difficult topic. In the workshop, we discuss challenges that come with working in a close environment, such as a research lab, and working with people from different backgrounds. Then, students work on building strategies to overcome these challenges. These strategies are discussed, and the moderators provide insight based on their own personal experiences.

Having an awareness of the communication styles of oneself and other team members is essential. Prior to the communication styles workshop, students take the Myer Briggs Indicator Personality Type test ${ }^{[18]}$. The test interpretation is discussed in an active learning environment, along with the effect of personality on how we communicate with one another. The students are asked to consider how to better communicate with their supervisor(s) based on their personality type. This includes making schedules, setting deadlines, discussing ideas, and getting feedback.

Academic integrity is an important part of a research career. During the course of the classes, academic integrity is covered throughout. Students are taught how to perform proper background search and how to do proper referencing. In addition, the students are familiarized with how to use reference management software such as Mendeley.

\subsection{Health and safety}

Health and safety attributes include, safe practices, mental health, and time management. During the safe practices class, we provide examples where health and safety were compromised in the faculty labs. The specific examples are shown to the class and discussed in groups. Through these real life examples, students learn about working safely in their lab, the dangers that exist, how to perform an environmental scan and how to get help. Afterwards, the students must identify safe and unsafe practices in their lab and perform the New Worker Safety Orientation.

During the mental health class, students are given a toolkit to determine where in the mental health continuum they are and what actions they can take at each point in the continuum. In 
addition, students in the upper years are invited to discuss how issues such as homesickness or weather affected their productivity, and they discuss strategies they took to remedy the situation.

Time Management and stress management are important skills for graduate students. In a workshop we designed, students learn to set goals, make priorities, manage their schedule, and contend with interruptions. They are also given tools on how to avoid procrastination ${ }^{[19,20]}$ and how to reduce their stress, including breathing exercises and framing exercises. In addition, several campus services are discussed so that the students can seek out further help if needed.

\subsection{Career building and leadership}

As part of the career building and leadership attributes students become familiar with different career options for engineers with a post graduate degree, informational job interviews, intellectual property, and entrepreneurship.

During industry sessions, industry professionals with higher educational degrees discuss how having a graduate degree affected their job prospects, and potential research or managerial career paths. Students gain insight into what their future career options (and limitations) may be.

A career service professional is invited to introduce the concepts of informational interviewing and discuss how to prepare for a successful interview in industry. The students also become familiar with basic concepts of networking and prepare elevator pitches for different jobs.

A guest speaker is invited from the University to discuss intellectual property (IP) and patent procedure with the students. The students also learn how they can protect their IP and where to seek help in case they want to file for patents.

Finally, we designed an entrepreneurship tournament, which we will implement this year. Student teams work together to develop a product of interest. The process starts from idea generation and moves through to final presentation, where a panel of judges chooses a winner.

\section{Implementation}

The program was launched in 2012 and has evolved to its current form with the aforementioned attributes. Class size has ranged from 30 to 155 engineering graduate students. The introduction of the two required courses with explicit professional skill development was part of an overall curriculum revision for the three departments currently involved in the program. In this revision, we removed the weekly seminars which has been given by students. As well, the course was merged across all three departments to provide the students with an integrated experience.

For each skill, we developed a workshop with a standard pattern: the skill was defined and its importance given; the skill was put into the context of the other skills; an active in-class exercise was provided to promote the students' understanding of the skill. In the workshops, we continually assessed the class comprehension of that subject knowledge, to determine if students lacked the subject knowledge or other necessary skills, such as problem solving skill. Overall, students have many opportunities to discuss interesting problems and issues each week. 
External speakers are invited for the lessons outside the instructor's expertise. For example, we invite a professor from the drama department to discuss voice projection, a counsellor from the health and wellness center to discuss stress, an entrepreneur to assist with the entrepreneurship tournament, and a career service professional to discuss networking and interview skills. Industry panels are invited to give their opinion on value of professional skills in industry. This has reinforced the importance of the material taught through the program.

The assessments are centered on the explicit objectives and criteria created for each unit, and on the synthesis of these units. Formative assessment include abstract writing and reviewing, a 3Minute Thesis (3MT) style presentation, an impact study, and a graduate student conference with oral presentations and posters. The assignments are not given numerical grades, but the students are provided with written feedback from instructors, Teaching Assistants and their peers. Oral presentations (3MT and student conference) are judged by faculty members, and the entrepreneurship tournament finalists are judged by entrepreneurs from industry and academia.

\section{Outcomes}

To date, the total participation across departments is over 350 graduate students. The students have consistently ranked the classes as highly effective and an excellent learning experience. Starting in Fall 2015, we have been teaching the courses collaboratively across departments, providing a more supportive learning environment, and an excellent platform for team-teaching and increased instructional conversation for those teaching the material.

Initially, some colleagues within the faculty opposed the program. Now most are active supporters, as they gained a better understanding of the program and saw the evidence of its effectiveness. Indeed, the evaluation of the program is vital to gain support from more faculty.

\subsection{Results from Student Feedback Survey (Quantitative)}

Student evaluation of the course was performed at the end of each term. Several factors were considered on the graduate students' experience and perception in terms of instruction, content, organization, learning experience and assignments.

As mentioned, the Professional Development Program has been offered since 2012 in the Electrical and Computer department (Elec.), and across three other engineering departments since Fall 2014. Unification of the departments into a single course allows the engineering faculty to ensure consistent quality of the education, while still giving graduate students the same valuable tools and skills. In addition, it provided a platform for sharing limited resources such as guest speakers, and increasing collaborations between students from different departments.

Results regarding graduate students' perception and acceptance are presented in Table 1, as well as a comparison of the results before and after the merge of the departments. Data was only available from the Elec. and Chem. departments. Based on these results, a high acceptance rate was observed in the course methodology and content, with greater than $75 \%$ in all categories. The highest variation within categories before and after the merge was seen in items 1, 9, 10, and 11 (see Figures 1 and 2). All four of these items decreased after the merge for the Chemical and Petroleum Engineering graduate students. The opposite was seen for the Electrical and Computer graduate students, where the four items increased after the merge. 
Table 1 Students perception of the professional development course before and after the merge.

\begin{tabular}{|c|c|c|c|c|c|c|c|}
\hline & \multirow{3}{*}{$\begin{array}{l}\text { Items Universal Student } \\
\text { Rating of Instruction }\end{array}$} & \multicolumn{4}{|c|}{ Separated classes } & \multirow{2}{*}{\multicolumn{2}{|c|}{$\begin{array}{l}\text { Joint class } \\
\quad \text { Fall } 2015\end{array}$}} \\
\hline & & \multicolumn{2}{|c|}{ Fall 2014} & \multicolumn{2}{|c|}{ Winter 2015} & & \\
\hline & & Chem. & Elec. & Chem. & Elec. & Chem. & Elec. \\
\hline 1 & Overall instruction & $88 \%$ & $91 \%$ & $86 \%$ & $85 \%$ & $79 \%$ & $85 \%$ \\
\hline 2 & Enough detail in course outline & $89 \%$ & $90 \%$ & $86 \%$ & $86 \%$ & $85 \%$ & $87 \%$ \\
\hline 3 & Course consistent with outline & $92 \%$ & $92 \%$ & $88 \%$ & $87 \%$ & $86 \%$ & $90 \%$ \\
\hline 4 & Content well organized & $91 \%$ & $90 \%$ & $89 \%$ & $87 \%$ & $88 \%$ & $89 \%$ \\
\hline 5 & Student questions responded to & $92 \%$ & $93 \%$ & $90 \%$ & $91 \%$ & $90 \%$ & $90 \%$ \\
\hline 6 & Communicated with enthusiasm & $91 \%$ & $96 \%$ & $89 \%$ & $93 \%$ & $89 \%$ & $91 \%$ \\
\hline 7 & Opportunities for assistance & $90 \%$ & $90 \%$ & $85 \%$ & $86 \%$ & $87 \%$ & $87 \%$ \\
\hline 8 & Students treated respectfully & $93 \%$ & $97 \%$ & $92 \%$ & $91 \%$ & $91 \%$ & $92 \%$ \\
\hline 9 & evaluation methods fair & $91 \%$ & $94 \%$ & $88 \%$ & $84 \%$ & $86 \%$ & $89 \%$ \\
\hline 10 & work graded in reasonable time & $92 \%$ & $95 \%$ & $88 \%$ & $85 \%$ & $86 \%$ & $86 \%$ \\
\hline 11 & I learned a lot in this course & $84 \%$ & $87 \%$ & $86 \%$ & $77 \%$ & $76 \%$ & $82 \%$ \\
\hline 12 & Support materials helpful & $88 \%$ & $90 \%$ & $88 \%$ & $85 \%$ & $85 \%$ & $89 \%$ \\
\hline
\end{tabular}

These observations could be due to the fact that after the merge of departments, some logistics issues needed to be overcame. First, given that attendance is mandatory for all students to complete their graduate degree, monitoring attendance is a key factor. However, having a class size three times larger required additional logistics. In this case online tools facilitated the process. Second, teaching assistants were hired to support class activities, to motivate students, and to engage in class discussions. Finally, make up assignments were defined as alternatives for students to fulfill their absences along the course, so additional assistance was needed in order to design, manage and review them on time. Implementation of these logistical measures could explain the slight decrease of acceptance after the merge.

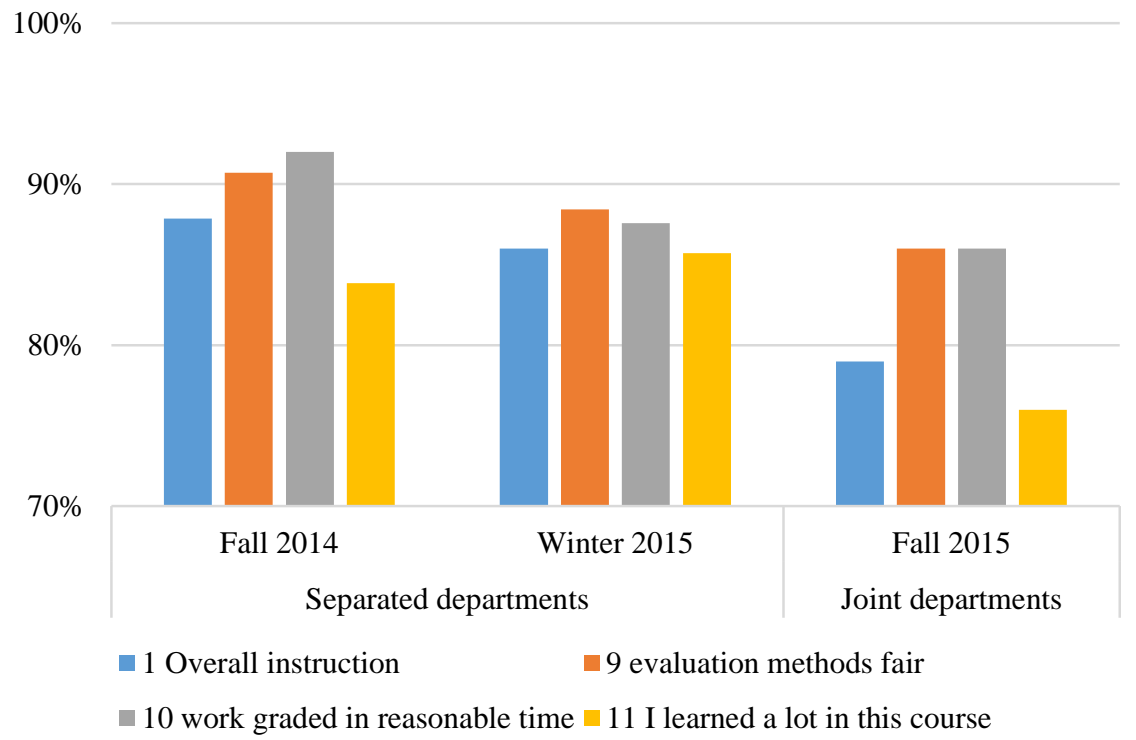

Figure 1. Historical results obtained from the Chemical and Petroleum Engineering Department graduate students 


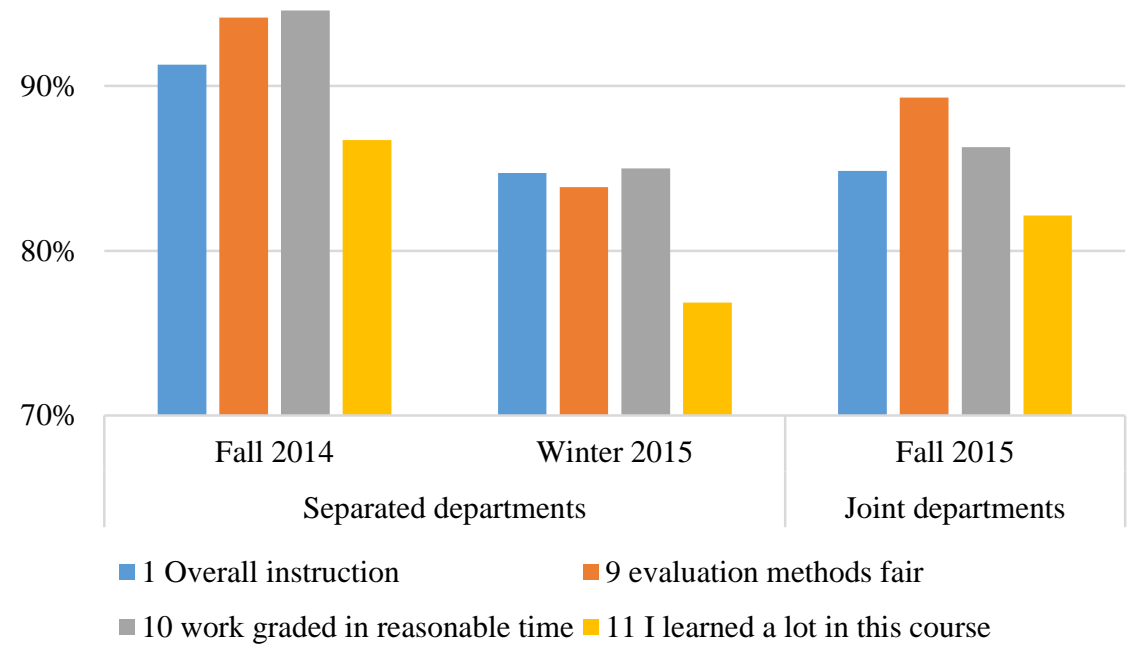

Figure 2. Historical results obtained from the Electrical and Computer department graduate students

\subsection{Results from Student Feedback Comments (Qualitative)}

Along with the survey, students were given an open-ended question ("Please provide general comments about the course") as an option to provide additional feedback. ${ }^{1}$

Across the two sections of the Fall 2014 course, a total of 91 written comments were received from the 108 students enrolled. These comments were analyzed using content analysis. Each comment was coded, and the codes were compiled and grouped into main themes. The final results showed four main themes: positive descriptors, class activities and topics, areas for improvement, and instructor-specific. Each of these will be discussed.

\section{Positive Descriptors}

More than two thirds of the comments positive descriptors (66/91). These included adjectives such as: enjoyable, interesting, helpful, fun, excellent, instructive. One student said, "Excellent seminar I learn a lot and I really enjoy the course."

\section{Class Activities and Topics}

About $29 \%$ of the students (26/91) mentioned specific class activities which they enjoyed during the semester. Most commonly referenced was the value that students received from the presentation practice required for the 3MT activity. For example, one student said "Really good to practice the presentation skills and how and where improvements are need it."

Many students also made reference to the fact that they enjoyed the interactive discussions and active learning component of the classes. For example, students said that they classes were "very

\footnotetext{
${ }^{1}$ For the first submission, only the Fall 2014 results will be discussed, as the Fall 2015 feedback comments have not yet been received. Results and comparisons will be added to the final paper.
} 
dynamic and encouraged student participation" and "the classes were dynamic and full of opportunities for improvement." The students appreciated the workshop-style format of the class.

\section{Areas for Improvement}

There were 20 students (22\%), who provided comments of areas the course could be improved. Of these, six students mentioned they disliked the timing of the course because it broke the day in half which made it difficult to work effectively on their experiments, research, or thesis. However, due the scheduling rules at the university, the timing of the course cannot be changed. The other areas for improvement were varied and included:

- "Could be further expanded by making it more specific on topics rather than generic."

- "Some classes were boring"

- "More guest speakers would be encouraged"

- "Less homework."

- "I do not feel that this course provided me with useful information"

- "Course recommended textbook was of average quality."

- "I hope that teacher can speak a bit slower."

\section{Instructor-Specific}

Lastly, 18 students (20\%), indicated positive comments specifically related to the instructor. The included comments on the organization and preparation of the course ("she was very organized and the classes were well prepared"), and the instructor enthusiasm ("she is very committed with this course and delivers it with enthusiasm.").

Overall, the comments provided from the students show that the feedback is mostly positive. Many students also mentioned that they appreciated the variety of topics covered and the focus on self-improvement throughout the course.

\section{Conclusions}

In this paper, we discussed the design, implementation and delivery of two graduate level professional development courses. Through these courses, we created series of workshops to develop professional skills we identified as most desirable (in self-management, communication, interpersonal and group skills, and lifetime learning). The workshops addressed both the attitude and cognitive dimensions. Our emphasis was on developing the skill through in-class "building" activities, then in-class and outside-class "bridging" the application of the skill to successful graduate degree, and finally through "extending" the application to everyday life.

Students rated the learning environment more positively than the previous format of the class. Specifically, they enjoyed the presentation practice through the 3-minute thesis activity, and the interactive class discussions. Thus far, the program is adopted in three engineering departments. In the last semester, the three classes were merged and the collaborative teaching method was implemented. Although, the sample data is not statistically significant at this point, the surveys show discrepancy in the perception of the new course format across the different departments. One group perceived it as an enhanced the learning environment, while the other group rated it slightly lower than the format of the individual classes. In the future, we will attempt to identify the cause of this difference and work on new methods for improving the delivery of the course for large class sizes. 


\section{References}

[1] D. Hurst, M. Cleveland-Innes and P. Hawranik, "Online graduate student identity and professional skills development", Canadian Journal of Higher Education, vol. 43, no. 3, 2013.

[2] M. C. Poock, "A model for integrating professional development in graduate education", College Student Journal, vol. 35, no. 3, Sept. 2001.

[3] S.W. Rogers and R.K. Goktas, "Exploring Engineering Graduate Student Research Proficiency with Student Surveys", Journal of Engineering Education, vol. 99, no. 3, July 2010.

[4] E. Enkin, "Supporting the Professional Development of Foreign Language Graduate Students: A Focus on Course Development and Program Direction”, Foreign Language Annals, vol. 48, no. 2, 2015.

[5] S.E. Watkins and R. Green, "Speaking and Writing Proficiency of International Graduate Students in Elective, Mentoring Environments", Journal of Engineering Education, vol. 92, no. 2, April 2003.

[6] E. Ramia, P. Salameh, I. F. Btaiche and A. H. Saad, "Mapping and assessment of personal and professional development skills in a pharmacy curriculum", BMC Medical Education, vol 16, no. 1, Jan. 2015.

[7] V. Venkatesh, J. Rabah, L. Lamoureux-Scholes, I. Pelczer, K. Urbaniak and F. Martin, "Development, Implementation, and Evaluation of a Professional Skills Development Program: The Case of Concordia University's GradProSkills”, Canadian Journal of Higher Education, vol. 44, no. 3, 2014.

[8] M. F. Cox, J.S. London, B. Ahn, J. Zhu, A.T. Torres-Ayala and S. Frazier, "Attributes of Success for Engineering Ph.D.s: Perspectives from Academia and Industry", in Proceedings of the 2011 ASEE, Annual Conference \& Exposition, Vancouver, BC, June 2011.

[9] M. F. Cox, J.S. London, B. Ahn, A.T. Torres-Ayala and K.D. Ramane, "Recommendations for Promoting Desirable Characteristics in Engineering Ph.D.s: Perspectives from Industry and Academia", in Proceedings of the 2012 ASEE, Annual Conference, San Antonio, Texas, June 2012.

[10] P. Hawranik and R. Chernish, "Graduate Student Educational and Professional Development Final Report 2009”, http://fgs.athabascau.ca/docs/gs_finalReport_2009.pdf, 2009, (Accessed January 2016).

[11] J. Zhu, C. Lynch and M.F. Cox, "Facilitating Graduate Students' Professional Development: Implementation and Evaluation of Learning Activities", in Proceedings of the 2012 ASEE, Annual Conference, San Antonio, Texas, June 2012.

[12] C. Lynch, J. Zhu and M.F. Cox, "Smoothing the Transition: Design, Implementation and Assessment of a "Preparing Future Professionals" Course for Graduate Students" in Proceedings of the 2011 ASEE, Annual Conference \& Exposition, Vancouver, BC, June 2011.

[13] H. Kearns, Presenting Your Research With Confidence: The step by step guide to powerful presentations, ThinkWell, 2011.

[14] C. Anderson, "What makes a great talk ... great", http://blog.ted.com/chris-anderson-on-what-makes-a-greattalk-great/, (accessed January 2016).

[15] I. Rae, "Presentation: Design 101", http://rene.chargingwombat.com, (accessed January 2016).

[16] Three Minute Thesis, http://threeminutethesis.org/, (accessed January 2016).

[17] H. Kearns and M. Gardiner, The Seven Secrets of Highly Successful Research Students, $3^{\text {rd }}$ ed., ThinkWell, 2012.

[18] The Myers \& Briggs Foundation, “My MBTI ${ }^{\circledR}$ Personality Type”, http://www.myersbriggs.org/my-mbtipersonality-type/, (accessed January 2016).

[19] S. R. Covey, The 7 Habits of Highly Effective People, 1st ed., Free Press, 1989.

[20] H. Kearns and M. Gardiner, Planning your PhD : all the tools and advice you need to finish your PhD in three years, ThinkWell, Adelaide, 2012. 